\title{
Resolução do problema de traçamento de raios em modelos sísmicos 2D usando o método paraxial.
}

Fabrício Lima \& Wilson Figueiró, Universidade Federal da Bahia.

\section{Copyright 2004, SBGf - Sociedade Brasileira de Geofísica}

Este texto foi preparado para a apresentação no I Simpósio de Geofísica da Sociedade Brasileira de Geofísica, São Paulo, 26-28 de setembro de 2004. Seu Sociedade Brasileira de Geofisica, São Paulo, 26-28 de setembro de 2004. Seu contúdo for revisado pela Comissão Tecno-cientica do I SR-SBG, mas náo necessariamente representa a opinia da SBGf ou de seus associados. E proibida a ciais sem prévia autorização da SBGf.

\section{Resumo}

A proposta do presente trabalho consiste em resolver o problema de traçamento de raios conectando posições de fontes àquelas onde se situam os receptores. Isto é, as posições da fonte e do receptor são conhecidas, e deseja-se achar a trajetória do raio que os une num campo de velocidades conhecido. Trata-se do clássico problema de traçamento de raios sísmicos que liga dois pontos: o conhecido "two-point Ray-tracing problem". Para certos modelos de campo de velocidades este problema pode ser resolvido analiticamente. Já para modelos mais complexos essas abordagens se tornam muito complicadas e incapazes de faze-lo. Um dos métodos que se apresentam, é o conhecido método paraxial e no presente trabalho são propostos algoritmos capazes de resolve-lo de uma maneira simples e objetiva, utilizando tal método.

\section{Introdução}

$\mathrm{Na}$ sismologia estuda-se a propagação de ondas sísmicas, originadas numa fonte e registradas em receptores (estações sismológicas), para modelar os possíveis diferentes dados sísmicos observados e buscando-se, com isso, compreender a estrutura interna da Terra. Um dos métodos para a geração (simulação de tais dados) baseia-se no traçamento de raios, que pode nos permitir o cálculo de dados tais como: tempo de trânsito e amplitude. Como fontes e receptores estão situados em posições bem definidas nos modelos, surge o problema colocado pela necessidade de conectar tais posições por um raio sísmico. Este problema tanto na sismologia quanto na sísmica são de mesma natureza, distinguindo-se apenas em termos de escala e na forma da superfície de observação: tendendo a ser plana na sísmica e esférica na sismologia. Entretanto, em ambos os casos, é possível e comum termos fontes ou receptores enterrados, o que não altera a natureza do problema. Como exemplos de domínios da sísmica que têm interesse na resolução do problema temos: migração (em migração reversa no tempo, tem-se o interesse de conectar fontes a pontos do modelo visando obter campos de tempo), modelagem (geração sintética de dados em pontos de observação), inversão (tomografia), teoria (resolução da equação do transporte usando o campo de tempos fornecido pelo traçamento de raio e a teoria do raio propriamente dita) e etc. Duas escolas se dedicam à resolução do problema: aquela que mantém fixos os dois extremos do raio e procura encurva-lo ("bending method") e aquela que mantém fixo um extremo (geralmente a posição da fonte) e varia a direção de "tiro" do raio ("shooting method"). Um exemplo dessa segunda abordagem para a solução do problema é o chamado método paraxial que é aqui usado (Figueiró \& Madariaga, 1999). Os movimentos da onda sísmica, considerados em termos de altas freqüências, obedecem às mesmas leis físicas da óptica, portanto podemos estudar os raios sísmicos explorando-se analogias e princípios ópticos. O princípio de Fermat é que governa a geometria do raio, isto é: a trajetória do raio é resultante da aplicação do princípio de Fermat à função que fornece o tempo de trânsito da onda em seu movimento ao longo de caminhos que conectam dois pontos dados (Popov, 2002). Em outras palavras: o caminho $C$ que torna tal tempo mínimo é a trajetória procurada.

\section{Metodologia/ Problema Investigado}

Um modo de fazer modelagem sísmica sem considerar todo o campo de ondas sísmicas preservando a sua estrutura e ao mesmo tempo proporcionando rapidez no processamento computacional é aquele realizado através do traçamento de raios sísmicos. É neste contexto que o problema de traçamento do raio que conecta dois pontos do campo de velocidades sísmicas ganha importância, sendo ele requisitado nos mais variados tópicos da exploração sísmica. Tendo em vista tal importância, o problema foi visto de forma peculiar. Fazendo em princípio uma análise analítica para mostrar uma visão mais simples do problema e em seguida trabalhando com campos mais complexos, onde, utiliza-se o método paraxial, que aproveita informações disponíveis num raio já traçado (raio central) para traçar um novo raio, vizinho, obtido através de uma perturbação do primeiro visando resolver o problema da conexão fonte-receptor, tal perturbação deve ser capaz de produzir uma diminuição da diferença entre o ponto de chegada, à superfície de referência, e a posição do receptor ou outro ponto qualquer de interesse no modelo.

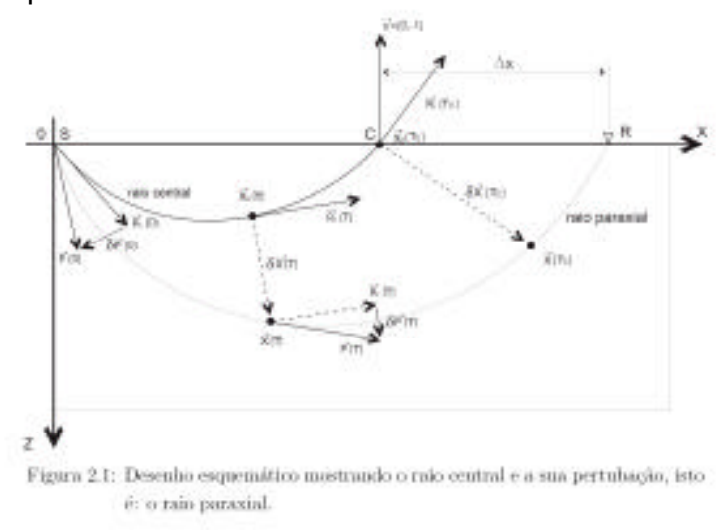


Buscando a criação de procedimentos matemáticos exatos ou com pequenas aproximações visando obter um método mais acurado e ao mesmo tempo buscar economia de tempo de processamento através da implementação de algoritmos computacionais que privilegiam a otimização.

\section{Resultados}

Para uma melhor visualização, trabalhamos com a cor azul para representar o primeiro raio central traçado, e a cor vermelha representando a trajetória do raio que resolve o problema.

No primeiro caso que estudamos, trabalhamos com um campo de velocidades descrito pela seguinte equação:

$$
\begin{array}{l|l}
V_{1}(x, z)-\frac{1}{\sqrt{a+b r+c^{2}}} & \begin{array}{l}
\text { E representado graficamente pela } \\
\text { Figura 1.1, gerando o modelo } \mathrm{M}_{1} .
\end{array}
\end{array}
$$
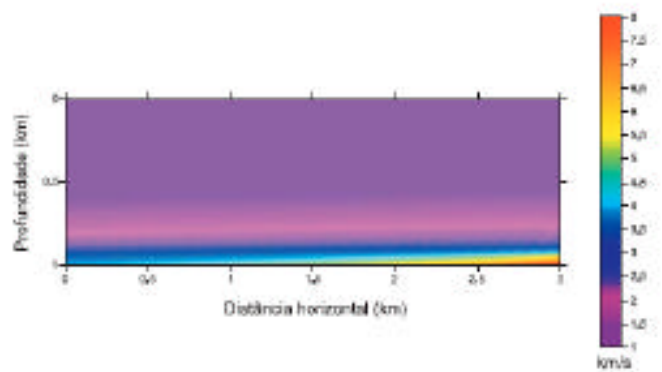

Figura 1.1: Canpo de velocidade $V_{1}$ eom $a=1,0 \mathrm{~s}^{2} \mathrm{~km}^{-2} ; \mathrm{b}=$ $-0,0156 \mathrm{e}^{2} \mathrm{~km}^{-3} \& \mathrm{c}--0,2377 \mathrm{a}^{2} \mathrm{~km}^{-3}$. Embora para efeito de resoluçāo do problema, a interpretayño geológicn do raodelo seja irrelewante, podeances dizer que ele pode sa visto ecano sando uma regīio comprerndida e comprimida entre o topo de um damo salino e a superficie.

Em todos os experimentos com $\mathrm{Ml}$ a posição da fonte $S$ foi mantida na superfície de observação $(z=0)$ em $x S=0,0$ $\mathrm{km}$. Quanto ao receptor $\mathrm{R}$, no primeiro experimento, ele foi colocado em $x R=0,5 \mathrm{~km}$ e $\mathrm{zR}=0,0 \mathrm{~km}$ como pode ser visto na Figura 1.2, na qual observa-se dois raios conectando $\mathrm{S}$ a $\mathrm{R}$ : um bem raso e outro tão profundo que excede a dimensão vertical do modelo.

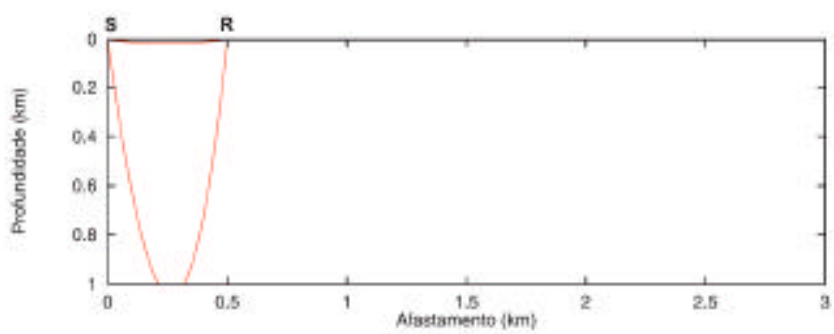

Figura 1.2: Conexầ de fonte a reoeptor situados ua superficie $z=0$ usando 0 método analitixs para o modelo $M_{j}$. A condenada $x$ da fonte $S, x_{s}$ é $0.0 \mathrm{~km}$ e o rexeptor estis localizado em $x_{R}=0,5 \mathrm{~km}$.

Agora podemos ver a resolução do problema utilizando o método paraxial para o mesmo modelo anterior, onde observamos uma boa resposta do método, resolvendo o problema com apenas 4 iterações. Como podemos ver na Figura 2.2.

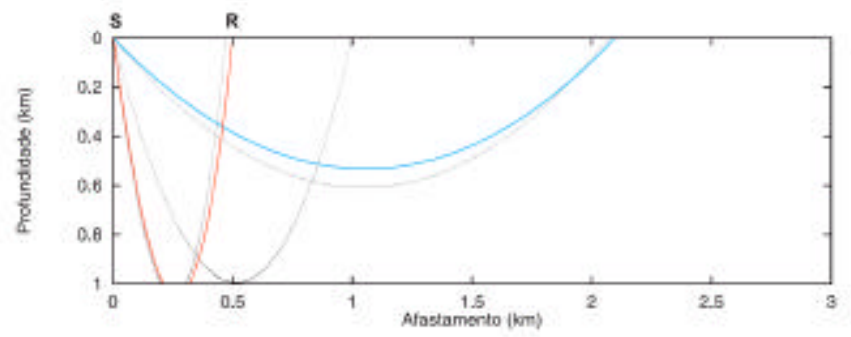

Figura 2.2. A fonte $\mathrm{S}$ é conectada à poriçio, $R=0,5 \mathrm{~km}$, do receptor, usando o método paraxial em 4 iterascós.

Foram feitos diversos modelos com diferentes campos de velocidades, buscando cada vez mais complexidade.

Trabalhando agora com um campo de velocidade do tipo:

$$
\begin{array}{l|l}
V_{2}=\frac{1}{\sqrt{a+b x+c z+x^{2}}} & \begin{array}{l}
\text { Podemos ter um modelo } \mathrm{M}_{\mathrm{II}-\mathrm{B},} \\
\text { representado graficamente pela } \\
\text { figura 2.9. }
\end{array}
\end{array}
$$

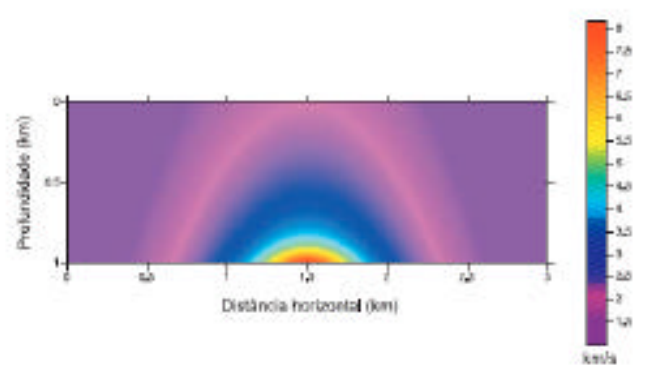

Figura 2.9 Campo de velocklade $V_{2}$ com $a=1,0 s^{2} \mathrm{~km}^{-2} ; b=-1,0 \mathrm{~s}^{2} \mathrm{~km}-\mathrm{s}$

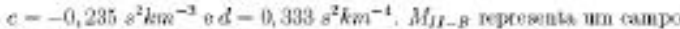
de veloeklades pascivel de set interpectado geologioarnente como uma dobrs anticlinal ou um domo

Agora, vemos uma situação radicalmente diferente do que foi visto antes. Como veremos, os raios se comportam de um modo não usual, entretanto isto não impede a resolução do problema.

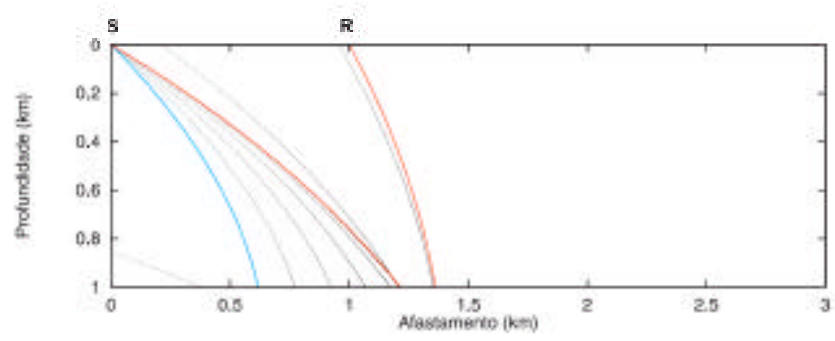

Figura 2.11: Rexeptor localizado em $R=1,0 \mathrm{~km} 6$ conectado à fonte $S \mathrm{em}$ to iteraçöes para o modelo $M_{U-B}$

Podemns ver anora ı ıma forma estendida da Finı ıra ? 11

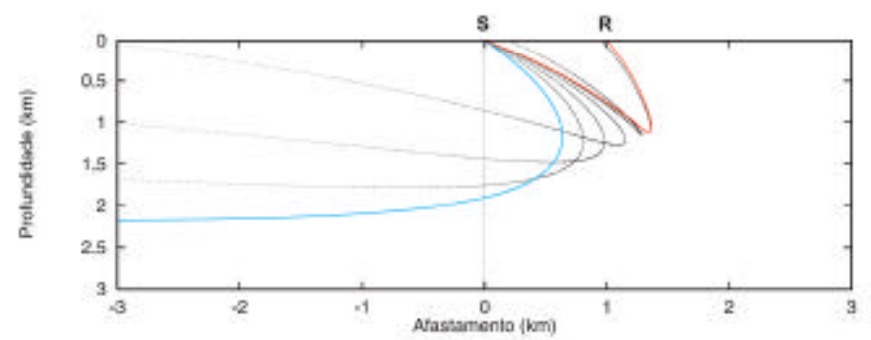

Figura 2.14: Versio estendida do experimento para o modelo $M_{\eta-B}$ com $R=$ $1.0 \mathrm{~km}$ 
Para tais raios ?x assume valores da ordem de $100,0 \mathrm{~km}$; entretanto, como vemos, isto não impede a resolução do problema.

\section{Discussão e Conclusões}

O presente trabalho foi capaz de resolver o problema do traçamento de raios entre dois pontos, para diversos modelos apresentados. Para o primeiro modelo estudado, obteve soluções analíticas e numéricas. Foi visto a excelente resolução do problema. Os modelos com campos de velocidades mais simples foram resolvidos pelo método paraxial, com um número reduzido de iterações. Observa-se que para modelos mais complicados, aumenta-se o número de iterações, porém isto não impede a solução do problema, assim como o fato de alguns raios saírem da região delimitada do modelo por uma borda diferente da superfície.

Como vimos também o modelo $\mathrm{M}_{\mathrm{II}-\mathrm{B}}$ nos mostrou que mesmo em casos que raios correntes produzam ?x muito grandes é possível encontrar solução.

\section{Agradecimentos}

Agradeço primeiramente, a Deus por gozar de plena saúde durante toda minha vida. À minha família que sempre me apoiou nos momentos mais difíceis, especificamente a meus pais, Dagoberto M. Lima e Maria de Fátima $P$. Monteiro, que sempre confiaram na minha escolha, até mesmo no início quando desconheciam a profissão. Ao grupo de colegas e professores do CPGG. À ANP pela bolsa de pesquisa que tive durante meus 2 últimos anos de curso, que foi imprescindível para a conclusão do trabalho. À minha namorada, Denise C. Brandão, que soube compreender certos momentos de agonia. À Petrobrás pelo grande apoio de seus funcionários, nos capacitando e nos proporcionando uma maior aproximação com a indústria.

\section{Referências}

AKI, K., \& RICHARDS, P.G., 1980. Quantitative Seismology: Theory and Method, W.H. Freeman and Co., San Francisco.

CERVENÝ, V., 1987. Ray Method for Three-Dimensional Seismic Modeling. Petroleum Industry Course, The Norwegian Institute of Technology.

FIGUEIRÓ, W. M., \& MADARIAGA, R. I., 1999. Threedimensional two-point paraxial ray-tracing problem in presence of caustics, $6^{\text {th }}$ International Congress of the Brazilian Geophysical Society, CDROM, Rio 99, Rio de Janeiro.

FIGUEIRÓ, W. M., \& MADARIAGA, R. I., 2000. A Method to avoid caustic arrival points, 2000 Techinical Program Expanded Abstracts, SEG International Exposition and $70^{\text {th }}$ Annual Meeting, Calgary, Alberta, Canada.
POPOV, M. M., 2002. Ray Theory and Gaussian Beam Method for Geophysicists, Salvador, EDUFBA.

SHERIFF, R. E., 2002. Encyclopedic Dictionary of Applied Geophysics, 13 Geophysical References Series, Fourth Edition, Society of Exploration Geophysicists, Tulsa, USA. 


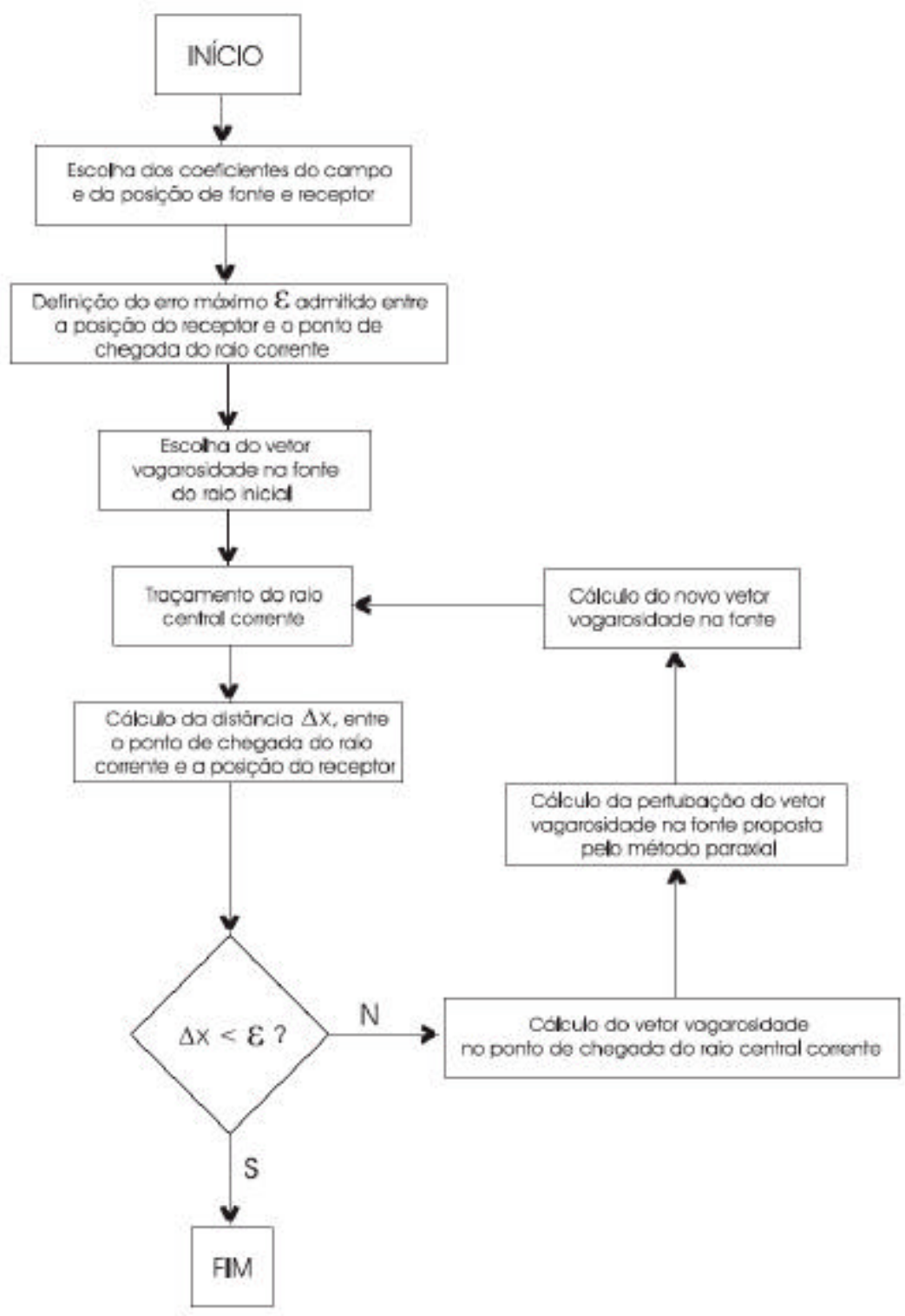

Figura B.1: Fluxograma simplificado dos algoritmos computacionais usados 